Veraneio marítimo na metrópole: o caso de Aquiraz, Ceará-Brasil Alexandre Queiroz Pereira, Eustógio Wanderley Correia Dantas

\title{
VERANEIO MARÍTIMO NA METRÓPOLE: o caso de Aquiraz, Ceará-Brasil
}

\section{Maritime summer vacation in the metropolis: the case of Aquiraz, Ceará - Brazil}

\author{
Alexandre Queiroz Pereira \\ Mestre em Geografia pela Universidade Federal do Ceará \\ aqp@ufc.br
}

Eustógio Wanderley Correia Dantas Prof. Dr. do Departamento de Geografia da Universidade Federal do Ceará eustogio@pq.cnpq.br

Artigo recebido para publicação em 27/02/08 e aceito para publicação em 01/09/08

RESUMO: As modernas práticas marítimas, em especial o veraneio, representam novas possibilidades de aproximação da sociedade com o mar, destacando o espaço litorâneo como prioritário para o lazer e moradia das populações das grandes aglomerações urbanas. Desta forma, a urbanização torna-se processo dialeticamente relacionado à disseminação da maritimidade moderna. Para compreender este processo, tomar-se-á como estudo de caso a expansão do veraneio marítimo em direção ao espaço litorâneo de Aquiraz. O cerne é entender a influência da Metrópole na diluição do veraneio marítimo no espaço revelado como litoral, em destaque as zonas de praia, inscritas ao tecido urbano da Região Metropolitana de Fortaleza. Os veranistas, os empreendedores imobiliários, o poder público municipal e estadual são sujeitos sociais envolvidos no processo gerador de uma morfologia urbana descontínua, caracterizada por parcelamentos urbanos e por aglomerados de segundas residências. Evidencia-se, nestes termos, a valorização dos espaços litorâneos como condicionante para a expansão da Metrópole.

Palavras chave: Práticas marítimas modernas, veranista, espaço litorâneo, urbanização.

ABSTRACT: The modern maritime practices, especially the summer vacations, represent new possibilities to come near the society of the sea, highlighting the coastal area a priority for leisure and living of the populations of major cities. This way, the growth urbanization process becomes a dialectically linked to the spread of modern maritimidade. To understand this process, will be study the case of expansion of the summer sea toward the coastal area of Aquiraz The point is to understand the influence of Metropolis in the dilution of the summer vacations sea in the space perceived as the coastline, highlights the areas of beach, entered the urban space of the metropolitan region of Fortaleza.

People who summer vacation, the real estate business, and the public power municipal and state social subjects are involved in the process of creating an urban morphology discontinuous, characterized by urban division's city and by clusters of second homes. There is, in these terms, to increase the value of coastal areas as condition to the expansion of the Metropolis.

Key words: Modern maritime practices, coastal area, growth urbanization process 


\section{INTRODUÇÃO}

Os espaços litorâneos cumprem funções estratégicas na vida econômica e social brasileira. No Ceará, mais de $65 \%$ da população vive à beira mar (MORAES, 1999), denotando um gênero de valorização litorânea advinda de facetas socioculturais (mudança no imaginário social que condiciona a disseminação das práticas marítimas modernas), tecnológicas (a chegada do automóvel, a eletrificação, as telecomunicações) e socioeconômicas (valoração dos imóveis, aumento do preço da terra e especulação) (DANTAS, 2000).

Parafraseando Madruga (1992), representaria "aumento de intensidade nas relações econômicas e sócio-culturais das sociedades humanas com o litoral e o mar" (MADRUGA, 1992, p. 33).

Os banhos de mar com caráter terapêutico em épocas anteriores, e de lazer em tempos mais recentes; do veraneio marítimo reforçando uma prática interiorana, e do turismo associado aos banhos de mar (URBAIN, 1995), redimensionam as cidades com o incremento de áreas até então dedicada às atividades tradicionais, em especial a portuária e a pesca artesanal.

Expressão representativa deste fenômeno é o veraneio marítimo, prática relacionada aos primeiros ensaios de urbanização dos espaços litorâneos no Ceará, entendidos aqui como processo social, historicamente constituído e que destaca o mar e o marítimo como elementos inseridos no cotidiano da sociedade urbana (DANTAS, 2002).

No Ceará, o morar ocasionalmente próximo ao mar, ganha impulso a partir do final dos anos 1960 início dos 1970, extrapolando os limites circunscritos pela capital Fortaleza (DANTAS, 2002) e denotando como os novos significados atribuídos às praias desperta nos citadinos a valorização no residir em uma área litorânea tornando este espaço um produto a ser consumido.

Antes da institucionalização da Região Metropolitana de Fortaleza (RMF- 1973), a propagação das segundas residências destinadas ao veraneio marítimo nos Municípios de Caucaia e Aquiraz já representava uma das formas de expansão do tecido urbano de Fortaleza. Com a oficialização da RMF - fato ocorrido em 1973 - esta atividade sócioespacial tornou-se efetivamente responsável pelo prolongamento da Metrópole e sua região urbana.

Tal fenômeno ganha peso nos anos 19902000, aparecendo como padrão de expansão associado à região metropolitana no Ceará (PEREIRA, 2006). Fato esse demonstrado nas maiores freqüências de concentração nos municípios de Fortaleza, Caucaia, Aquiraz e São Gonçalo do Amarante. (Tabela 1).

O município a ser estudado, Aquiraz, ocupa a terceira posição, perdendo tão somente para Fortaleza e Caucaia. Fortaleza com 4.112 residências secundárias $(28,6)$ em 1991 e $7.942(32,2)$ em 2000. Caucaia dispondo de 3.877 residências secundárias $(27 \%)$ em 1991 e de 6.540 em 2000 (26,5\%). Aquiraz contando com 2.657 residências secundárias $(18,5 \%)$ em 1991 e de 4.536 (18,4\%) em 2000 (Tabela 1).

O fluxo de pessoas, mercadorias, intervenções e investimentos, fomentados pelo processo de valorização do espaço litorâneo, definiram a integração das praias de Aquiraz ao contexto metropolitano; despertando um outro gênero de ocupação, responsável pela dinamização dos espaços litorâneos na região metropolitana e gerando, a partir da capital, um novo fluxo de veranistas ali residentes. 
Veraneio marítimo na metrópole: o caso de Aquiraz, Ceará-Brasil Alexandre Queiroz Pereira, Eustógio Wanderley Correia Dantas

Tabela 1: Residências secundárias dos municípios da Região Metropolitana de Fortaleza (CE) - 1991 e 2000

\begin{tabular}{|c|c|c|c|c|c|}
\hline & \multirow[b]{2}{*}{ Municípios } & \multicolumn{2}{|l|}{1991} & \multicolumn{2}{|l|}{2000} \\
\hline & & $\begin{array}{r}\text { Número de } \\
\text { segundas } \\
\text { residências }\end{array}$ & $\%$ & $\begin{array}{l}\text { Número de } \\
\text { segundas } \\
\text { residências }\end{array}$ & $\%$ \\
\hline 1 & Chorozinho & 100 & 0,7 & 144 & 0,6 \\
\hline 2 & Guaiúba & 123 & 0,9 & 144 & 0,6 \\
\hline 3 & Itaitinga* & 0 & 0,0 & 243 & 1,0 \\
\hline 4 & Pacatuba & 414 & 2,9 & 289 & 1,2 \\
\hline 5 & Pacajus & 189 & 1,3 & 317 & 1,3 \\
\hline 6 & Horizonte & 282 & 2,0 & 390 & 1,6 \\
\hline 7 & Maracanaú & 344 & 2,4 & 474 & 1,9 \\
\hline 8 & Maranguape & 380 & 2,6 & 765 & 3,1 \\
\hline 9 & Eusébio & 695 & 4,8 & 1043 & 4,2 \\
\hline 10. & S. Gonçalo Amarante & 1197 & 8,3 & 1822 & 7,4 \\
\hline 11. & Aquiraz & 2657 & 18,5 & 4536 & 18,4 \\
\hline 12. & Caucaia & 3877 & 27,0 & 6540 & 26,5 \\
\hline 13. & Fortaleza & 4112 & 28,6 & 7942 & 32,2 \\
\hline & TOTAL & 14370 & 100 & 16707 & 100,00 \\
\hline
\end{tabular}

Fonte: IBGE, Sinopse 1991 e 2000.

Nossa contribuição ao entendimento do processo de formação do espaço litorâneo metropolitano cearense faz-se, nestes termos, mediante análise das relações estabelecidas entre Fortaleza (sua sociedade) e Aquiraz. Para tanto, tornase relevante compreender como os fortalezenses e os empreendedores imobiliários construíram, na área litorânea de Aquiraz, o processo de expansão do tecido urbano de Fortaleza.

\section{Formação do espaço litorâneo metropolitano: intersecção Fortaleza-Aquiraz}

Mesmo com a existência de antigas comunidades em partes do litoral e seus moradores, o espaço litorâneo é qualificado como relevante pelos investidores imobiliários somente a partir da chegada dos primeiros veranistas, ou seja, com a instituição das práticas marítimas modernas (DANTAS, 2000).

Fortaleza, maior cidade do Estado e matricial da Metrópole, é a maior responsável pela emissão de veranistas às zonas de praia do Ceará. A propagação do desejo pelo marítimo, a formação de uma classe média em Fortaleza (funcionários públicos estaduais e federais, comerciantes e autônomos), o crescente deslocamento com o automóvel, a construção de uma infra-estrutura viária satisfatória e a relativa proximidade, são elementos importantes para a valorização da orla marítima de Aquiraz, e consecutivamente, o aumento de segundas residências construídas no Município.

Pode-se enumerar uma série de argumentos que tornam a relação Fortaleza-espaço litorâneo de Aquiraz um caso importante para compreender a integração e expansão metropolitana. Além de manter relações com Fortaleza desde o período colonial e compor a RMF desde sua instituição, Aquiraz é o único município metropolitano no litoral leste, sendo suas praias uma das primeiras a receber os veranistas fortalezenses.

Tal afirmação lhe dá posição de destaque como importante pólo de lazer tratando-se do município com a maior freqüência de residências 
Veraneio marítimo na metrópole: o caso de Aquiraz, Ceará-Brasil Alexandre Queiroz Pereira, Eustógio Wanderley Correia Dantas

secundárias em relação aos domicílios totais (18,39\% em 1991 e $21,14 \%$ em 2000), seguido por São Gonçalo do Amarante (14,20\% em 1991 e
14,68\% em 2000), Caucaia (8,34\% em 1991 e 8,30\% em 2000) e Fortaleza $(0,92 \%$ em 1991 e 1,29\% em 2000).

Tabela 2: Número de domicílios, de residências secundárias e porcentagem segundo ao total de domicílios Região metropolitana de Fortaleza - 1991 e 2000.

\begin{tabular}{|c|c|c|c|c|c|c|}
\hline \multirow[b]{2}{*}{ Municípios } & \multicolumn{3}{|c|}{1991} & \multicolumn{3}{|c|}{2000} \\
\hline & $\begin{array}{l}\text { Numero de } \\
\text { domicílio } \\
\text { particular }\end{array}$ & $\begin{array}{l}\text { Numero de } \\
\text { segundas } \\
\text { residências }\end{array}$ & $\%$ & $\begin{array}{l}\text { Numero de } \\
\text { domicílio } \\
\text { particular }\end{array}$ & $\begin{array}{l}\text { Numero de } \\
\text { segundas } \\
\text { residências }\end{array}$ & $\%$ \\
\hline Total & 601349 & 14370 & 2,39 & 879314 & 24649 & 2,80 \\
\hline \multicolumn{7}{|l|}{ Municípios } \\
\hline litorâneos & 515467 & 11843 & 2,30 & 730583 & 20840 & 2,85 \\
\hline Aquiraz & 14449 & 2657 & 18,39 & 21457 & 4536 & 21,14 \\
\hline Caucaia & 46462 & 3877 & 8,34 & 78837 & 6540 & 8,30 \\
\hline Fortaleza & 446125 & 4112 & 0,92 & 617881 & 7942 & 1,29 \\
\hline \multicolumn{7}{|l|}{ S. Gonçalo } \\
\hline Amarante & 8431 & 1197 & 14,20 & 12408 & 1822 & 14,68 \\
\hline \multicolumn{7}{|c|}{ Municípios não } \\
\hline litorâneos & 85882 & 2527 & 2,94 & 148731 & 3809 & 2,56 \\
\hline Chorozinho & 3980 & 100 & 2,51 & 17171 & 144 & 0,84 \\
\hline Eusébio & 5723 & 695 & 12,14 & 9832 & 1043 & 10,61 \\
\hline Guaiúba & 4315 & 123 & 2,85 & 5611 & 144 & 2,57 \\
\hline Horizonte & 4865 & 282 & 5,80 & 10075 & 390 & 3,87 \\
\hline Itaitinga & - & - & - & 8074 & 243 & 3,01 \\
\hline Maracanaú & 34616 & 344 & 0,99 & 48159 & 474 & 0,98 \\
\hline Maranguape & 8387 & 380 & 4,53 & 22955 & 765 & 3,33 \\
\hline Pacajus & 8146 & 189 & 2,32 & 12698 & 317 & 2,50 \\
\hline Pacatuba & 15850 & 414 & 2,61 & 14156 & 289 & 2,04 \\
\hline
\end{tabular}

Fonte: IBGE, Sinopse 1991 e 2000.

Esta nova relação entre a sociedade fortalezense e o mar, representada pelo desejo em veranear nas praias próximas à Capital, incentivou a demanda pela busca de um espaço litorâneo parcelado, disponível para consumo. Tal dado faz com que o litoral de Aquiraz ganhe vida própria, independente da sede e associada à Fortaleza (BERNAL, 2004).

Por conseguinte, o Plano Diretor de Desenvolvimento Urbano de Aquiraz, 2001/2002 (PDDU), apresenta compartimentação do espaço municipal peculiar, com indicação de segmento litorâneo associado ao fluxo de veranistas: limitado ao norte pelo Oceano Atlântico e ao sul pela rodovia estadual CE 040 (figura 1).

Esta área coincide com os limites dos distritos de Jacaúna, Tapera e Distrito-Sede. Nesta delimitação, encontra-se uma morfologia espacial intrínseca ao fenômeno social da maritimidade moderna: loteamentos urbanos próximos ao mar, aglomerados de segundas residências e empreendimentos turísticos.

Conforme destaca a figura 1 , constituem este espaço os núcleos de veraneio de Porto das Dunas, 
Veraneio marítimo na metrópole: o caso de Aquiraz, Ceará-Brasil Alexandre Queiroz Pereira, Eustógio Wanderley Correia Dantas

Prainha, Iguape e Batoque destinado, principalmente, à população fortalezense.

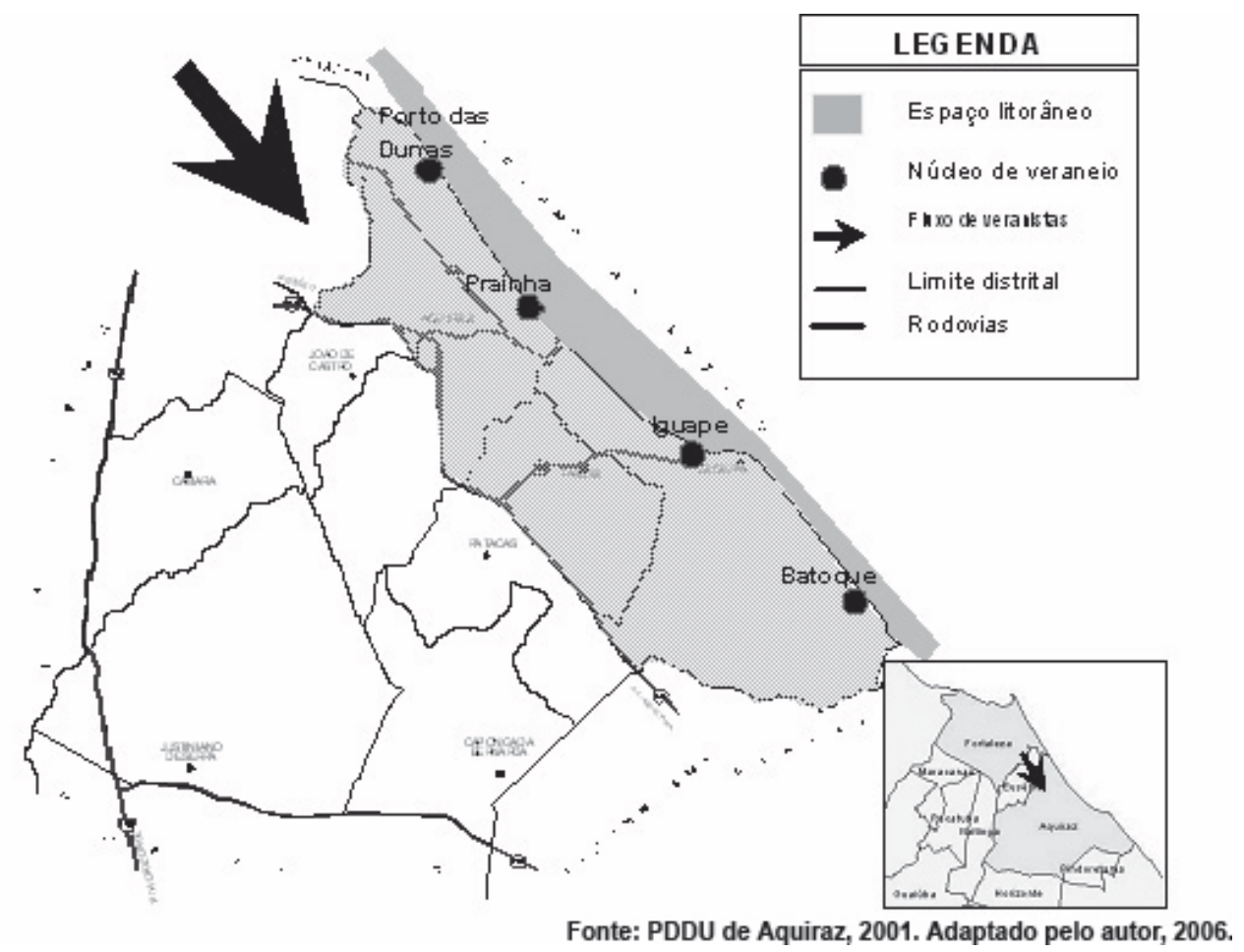

Figura 1. O espaço litorâneo: intersecção Aquiraz - Fortaleza.

Os primeiros veranistas em Aquiraz construiriam suas segundas residências nas localidades litorâneas de Prainha e Iguape, empreendendo um gênero de uso diferente ao dos moradores destas localidades, organizados em torno da pesca artesanal, do extrativismo e de uma pequena agricultura de subsistência, atividades estas essenciais para a manutenção de sua sobrevivência, tanto em termos econômicos como culturais.

Como o exemplo ocorrido em Fortaleza, este tipo de valorização desencadeia a construção de um quadro conflituoso que desencoraja a apropriação das zonas de praia pelas populações mais pobres, em especial os pescadores, pois evidencia a oposição entre duas lógicas de ocupação: uma ligada ao espaço da produção e a outra ao espaço do consumo (LEFEBVRE, 1986).

No primeiro caso, o espaço da produção, a natureza transformada representa um dom, uma resposta a certas necessidades individuais. Esta lógica provocou a transformação dos espaços litorâneos em lugar de trabalho, das festas e da habitação dos pescadores artesanais.

No segundo caso, o espaço do consumo, assiste à transformação da natureza em mercadoria oferecida aos apreciadores das praias. Tal redimensionamento possibilita o estabelecimento dos veranistas e desperta concomitante, a lógica de expulsão de seus antigos moradores.

O interesse maior dos veranistas se dá na possibilidade de juntar o ato de residir com ato de lazer e descanso na proximidade do mar. Este fato pode ser verificado nas construções que ocupam linearmente a orla, praticamente encontrando o esparramar das ondas. 
No final da década de 1970 e início da década de 1980, a valorização do espaço litorâneo de Aquiraz se tornou mais complexa com o aumento da demanda por outras áreas mais próximas ao mar. Especificamente podemos citar as localidades de Presídio (próximo ao Iguape), Porto das Dunas e Batoque, esta já numa menor intensidade.

Concomitantemente, grande quantidade de loteamentos $^{1}$ foi aprovada e implantada, não nas praias, mas ao seu redor, formando um cinturão de lotes postos à venda por empresas imobiliárias (construtoras e corretoras), que vislumbravam a realização de negócios lucrativos.

O Poder público, nas esferas municipal e estadual, participou efetivamente deste processo, concedendo licenças para as construções, assim como se responsabilizando pela implantação de infraestrutura, ou seja, a pavimentação de estradas de acesso e a eletrificação das áreas. Porém, as normatizações no contexto municipal, só seriam elaboradas com a organização do Plano Diretor de Desenvolvimento Urbano do Município de Aquiraz, no ano de 2001.

Evidencia-se, nesta perspectiva, a instalação de um padrão mercantil-urbano de acesso a terra, uma das transformações mais sensíveis relacionadas à valorização litorânea, assentada nas atividades de veraneio.

\section{Os parcelamentos e as estratégias dos empreendedores imobiliários em Aquiraz}

As primeiras residências construídas em terrenos da Marinha e os parcelamentos iniciais são exemplos de uma nova relação da sociedade urbana fortalezense com os espaços litorâneos. No final da década de 1960, grandes empregadores e dirigentes públicos/privados foram responsáveis pela propagação, no contexto do Estado do Ceará, do gosto pelo lazer na praia, em especial pelo veraneio. Estes sujeitos sociais, além de construírem suas segundas residências em Aquiraz se apropriaram de terras à beira-mar, vendendo-as, posteriormente, em lotes para conhecidos e demais interessados de mesmo poder aquisitivo semelhante ao seu.

Contudo, a partir da década de 1970, a valorização do espaço litorâneo e a expansão dos loteamentos consolidaram-se com investimentos e empreendimentos de empresas imobiliárias assentadas em Fortaleza.

O parcelamento do solo em lotes urbanos implica em mudança de concepção no que cerne ao uso e acesso ao espaço, uma vez que ele se transformar em mercadoria, disponível no circuito da troca, na esfera da comercialização. (CARLOS, 1999, p. 175).

A conseqüência direta deste novo direcionamento é o aumento do número de loteamentos. Se no início dos anos 1970 eles não existiam próximos às praias de Aquiraz, atualmente eles aparecem destacadamente na paisagem de todos os distritos (Sede, Jacaúna e Tapera), conforme indicado no Plano de Estruturação Urbana de Aquiraz - parte integrante do Plano Diretor de Desenvolvimento Urbano:

...o parcelamento e ocupação da terra têm ocorrido obedecendo a uma dinâmica de maior intensidade na faixa de acompanhamento litorâneo proveniente de Fortaleza até a Prainha e no corredor da Sede até a Prainha e, ainda, no segmento do litoral do Distrito de Jacaúna correspondente ao Presídio, Iguape, e Barro Preto. (AQUIRAZ, 2001, p. 16).

Tal gênero de pressão esbarra nos limites explícitos pelas leis, como consta no artigo $3^{\circ}$ da Lei Federal $n^{\circ} .6766 / 79$, que só admite parcelamento do solo para fins urbanos em zonas urbanas, de expansão urbana ou de urbanização especificada, assim definida pelo plano diretor ou aprovadas por lei municipal.

\footnotetext{
1 Considera-se loteamento a subdivisão de gleba em lotes destinados a edificação, com abertura de novas vias de circulação, de logradouros públicos ou prolongamento, modificação ou ampliação das vias.
} 
Veraneio marítimo na metrópole: o caso de Aquiraz, Ceará-Brasil Alexandre Queiroz Pereira, Eustógio Wanderley Correia Dantas

A primeira lei de uso e ocupação do solo aprovada em Aquiraz, de 18 de dezembro de 1984, compreendia somente à faixa litorânea entre a foz do rio Catu e a embocadura do rio Pacoti, desconsiderando o restante do Município.

A faixa litorânea à qual a lei se refere abrange, exatamente, os núcleos Prainha e o Porto das Dunas, inclusos em três zonas de uso e ocupação:

- zona residencial de baixa densidade demográfica, na qual se instalariam residenciais unifamiliares;

- zona residencial de média densidade, que servia tanto para residências unifamiliares como multifamiliares;

- zona de uso liberado, destinada às residências, como também para o comércio, serviços e/ou equipamentos. Não eram permitidos, segundo a lei, usos voltados ao comércio atacadista e à produção industrial.

No entanto, mesmo limitada à pequena área do Município, sem critérios técnicos e de acordo com os interesses dos incorporadores (na comercialização da terra) e da própria municipalidade (em aumentar a receita municipal mediante cobrança do Imposto Predial e Territorial Urbano - IPTU) ${ }^{2}$, a lei mencionada foi utilizada para nortear e licenciar empreendimentos na totalidade do município.

Conseqüência dessa fragilidade é a adoção de duas estratégias: uma relacionada aos incorporadores, sequiosos em comercializar lotes cada vez maiores de terra no mercado, e outra à municipalidade, buscando desenvolver ações de estruturação e planejamento.

A primeira estratégia implica na oferta de lotes a preços mais populares e/ou financiados, conseqüência direta da precariedade infra-estrutural.
Tal característica dos loteamentos é evidenciada por Montenegro Jr. (2004):

...no início, a expansão imobiliária no litoral de Aquiraz possuía características de uso ligadas, essencialmente, às atividades de veraneio, onde os loteamentos, em geral, são implantados sem a mínima infra-estrutura urbana necessária, contando apenas com acessos precários em terra batida, rede elétrica, telecomunicação, coleta de lixo, mercearias e pequenos comércios de apoio que surgem espontaneamente, nem sempre satisfatórios às necessidades temporárias e provisórias dos veranistas (MONTENEGRO JR., 2004, p. 130).

A segunda estratégia, ao implementar um plano de estruturação urbana (em 1999), favoreceu o uso indiscriminado do solo, um dos maiores problemas identificados na morfologia urbana de Aquiraz.

O Poder público, através de leis de uso e ocupação do solo, viabiliza a construção do padrão mercantil-urbano de acesso a terra.

Ao longo das três últimas décadas do século $\mathrm{XX}$, cerca de 70 (setenta) projetos de parcelamentos urbanos, de empresas imobiliárias sediadas em Fortaleza, foram aprovados. Nenhum deles, incluindo o mais famoso, Porto das Dunas, apresentava critérios legais próprios à instalação.

A tabela 3 apresenta a grande quantidade de empreendimentos construídos no espaço litorâneo de Aquiraz durante os anos 1970 e 1980, respectivamente $34,6 \%$ e $38,5 \%$ do total, período no qual se tem a expansão do veraneio em direção aos municípios metropolitanos. O Distrito Sede apresenta o maior número de parcelamentos cadastrados, 38 no total, destes 52,6\% instalados na década 1970 .

\footnotetext{
2 De acordo com, o Código Tributário de Aquiraz (Lei n. ${ }^{\circ}$ 566/2005), para fins de cobrança do Imposto Predial e Territorial Urbano, toda área onde existam pelo menos 02 (dois) dos seguintes itens abaixo, construídos ou mantidos pelo Poder Público, pode ser considerada zona urbana: i) Meio-fio ou calçamento, com canalização de águas pluviais; ii) Abastecimento de água; iii) Sistema de esgotos sanitários; iv) Rede de iluminação pública, com ou sem posteamento para a distribuição domiciliar; e v) Escola primária ou posto de saúde a uma distância máxima de três quilômetros do imóvel considerado.
} 
Veraneio marítimo na metrópole: o caso de Aquiraz, Ceará-Brasil Alexandre Queiroz Pereira, Eustógio Wanderley Correia Dantas

Tabela 3: Parcelamentos urbanos em Aquiraz/Distritos e década de instalação.

\begin{tabular}{lrrrrrr}
\hline \multicolumn{1}{c}{ Distritos } & $\mathbf{1 9 7 0}$ & $\mathbf{\%}$ & $\mathbf{1 9 8 0}$ & $\mathbf{\%}$ & $\mathbf{1 9 9 0}$ & $\mathbf{\%}$ \\
\hline Sede & 20 & $74 \%$ & 10 & $33 \%$ & 8 & $38 \%$ \\
Jacaúna & 3 & $11 \%$ & 17 & $57 \%$ & 8 & $38 \%$ \\
Tapera & 4 & $15 \%$ & 3 & $10 \%$ & 5 & $24 \%$ \\
\hline \multicolumn{1}{c}{ TOTAIS } & 27 & $100 \%$ & 30 & $100 \%$ & 21 & $100 \%$ \\
\hline
\end{tabular}

Secretaria de Planejamento, 2005.

Fonte: Prefeitura Municipal de Aquiraz

No Distrito-Sede, localiza-se dois dos maiores núcleos praianos: Porto das Dunas e Prainha. Porto das Dunas é peculiar por se firmar na década de 1980, com a construção do maior parcelamento de Aquiraz, tanto em quantidade de lotes como em volume de vendas, tratando-se, de acordo com informações da área técnica municipal, do "carro-chefe" de vendas no Município. Na figura 2 pode-se visualizar o traçado urbano linear do referido empreendimento, ligado à Fortaleza pela CE 025 (indicação da seta).

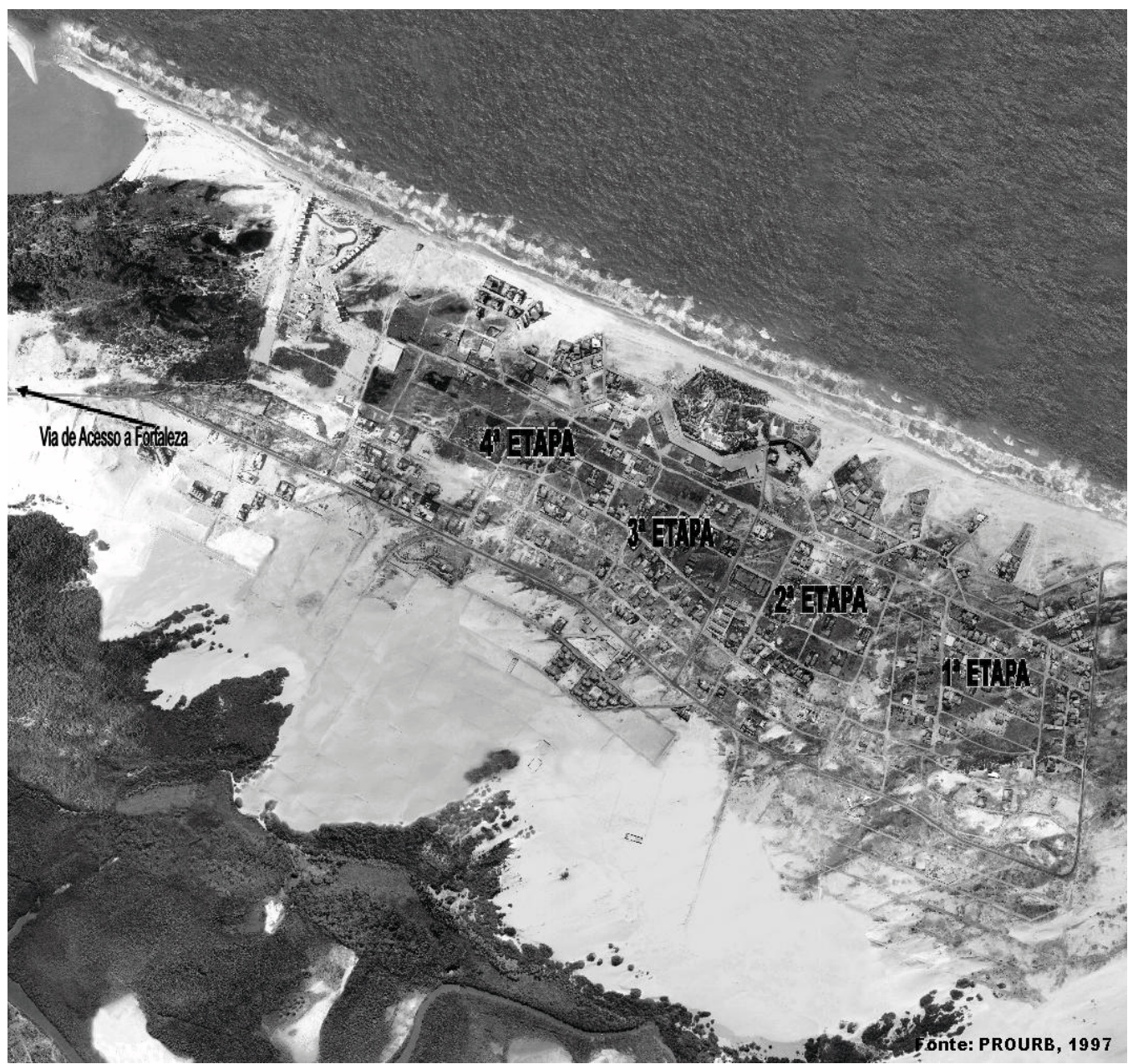

Figura 2. Foto aérea do loteamento Porto das Dunas em Aquiraz/CE.

Sociedade \& Natureza, Uberlândia, 20 (2): 93-106, DEZ. 2008 
Veraneio marítimo na metrópole: o caso de Aquiraz, Ceará-Brasil Alexandre Queiroz Pereira, Eustógio Wanderley Correia Dantas

Este empreendimento, o mais próximo à Fortaleza, aprovado em 1985 e localizado na praia homônima, é composto por quatro etapas, sendo a última subdivida em três partes, perfazendo o total de 2.432 (dois mil, quatrocentos e trinta e dois )lotes.

Tais lotes foram/são comercializados com os maiores valores (por metro quadrado) do litoral aquiraense. Os dados da Secretaria de Arrecadação de Aquiraz informam que a estimativa de preços, por lote, varia entre $\mathrm{R} \$ 20.000,00$ (vinte mil reais) e $\mathrm{R} \$$ 200.000,00 (duzentos mil reais).

Evidenciando o víeis econômico da valorização de tais espaços, o caso do Porto das Dunas exprime a relação entre a metrópole e os espaços litorâneos metropolitanos.
Entretanto, nada mais agressivo, em termos de área envolvida e de compradores, do que a estratégia utilizada por inúmeras imobiliárias especializadas em vendas a prazo de loteamentos "populares" no município: veraneio popular, de massa (URBAIN, 1995).

Estas empresas ampliam número de clientes com oferta de lotes a partir de R $\$ 77,00$ (setenta e sete reais) por mês (Figura 3). Destaca-se, dentre elas, a Imobiliária Henrique Jorge Pinho S.A., maior proprietária de empreendimentos do gênero em Aquiraz.

Os parcelamentos são anunciados em placas à margem das rodovias estaduais e em sua sede em Fortaleza.

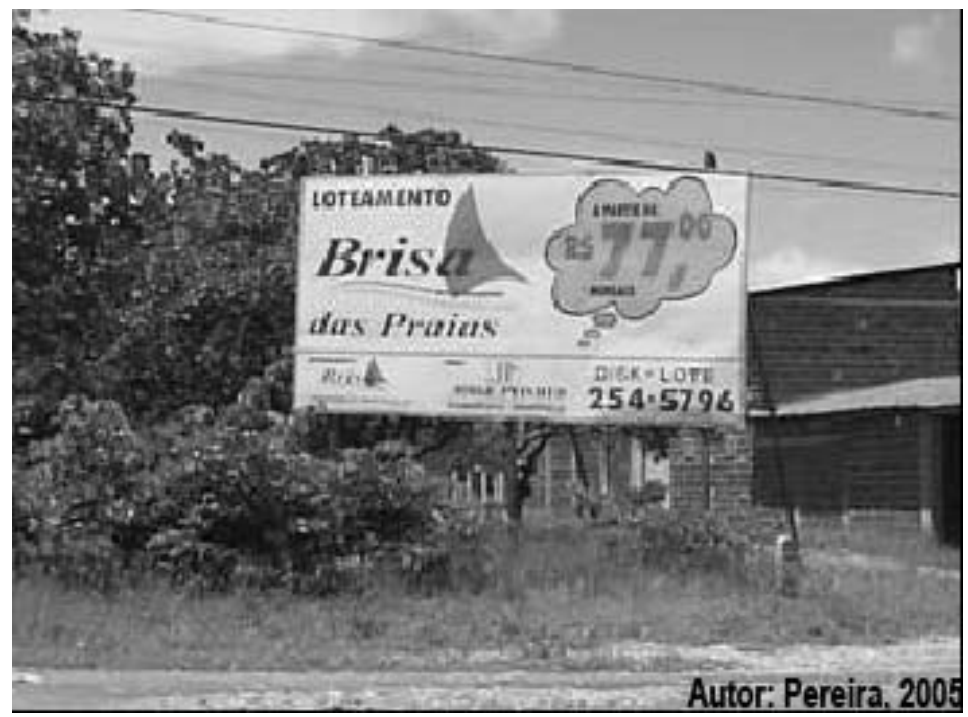

Figura 3. Outdoors na CE 040, distrito Sede.

Estes loteamentos não estão limitados aos distritos Sede e a Jacaúna. O distrito de Tapera, mesmo não apresentando linha de costa, também é comercializado como espaço litorâneo de Aquiraz.

Com uma localização estratégica, entre os Distritos Sede e Jacaúna, Tapera conta com 13 parcelamentos. Estes empreendimentos se inserem na lógica de valorização dos espaços, associada ao mar ou ao marítimo, como é evidenciado no nome de alguns destes lançamentos: Rotta del Mar, Caminho do Iguape e Brisa do Iguape.

A maioria destes empreendimentos dispõe-se de infra-estrutura precária, com grande parte dos lotes ainda desocupada, embora já existam algumas construções erguidas. 
Os veranistas e os empreendedores imobiliários fortalezenses tornaram-se, num período de três décadas, sujeitos propulsores das transformações da orla litorânea destas localidades.

O poder público municipal de Aquiraz, com leis pontuais e sem instrumentos técnicos de planejamento, estimulou a consolidação deste processo. Entretanto, somente com a elaboração do primeiro Plano Diretor Municipal, em 2001, foram discutidas as propostas para ocupação do espaço litorâneo de Aquiraz.

\section{O Plano Diretor e as propostas para o espaço litorâneo de Aquiraz}

As discussões do Plano Diretor nos conduzem à compreensão das influências e possibilidades do Poder Público Municipal em meio às transformações do espaço em referência. Põe-se em questão a autonomia do Município em relação à expansão metropolitana mediada pelo veraneio marítimo, destacando-se, principalmente, a lei de uso e ocupação do solo e o zoneamento proposto pelo PDDU.

O PDDU é uma ferramenta de suma importância para a gestão urbana e municipal. A partir de sua elaboração e revisão constante, uma determinada administração pode direcionar de maneira mais eficiente suas políticas públicas e avaliar a ordenação e ocupação do território.

Torna-se, porém, um documento de caráter político, à medida que, com o zoneamento proposto, certas áreas podem ser selecionadas em detrimento a outras para intervenções e investimentos, tanto públicos quanto privados.

No entanto, o zoneamento do solo em Aquiraz é determinado somente no ano de 2005, com aprovação de lei de uso e ocupação do solo, cujo objetivo principal é, a partir da ampliação da capacidade infra-estrutural, incentivar a ocupação em áreas com concentração e com tendência à concentração de atividades.
O zoneamento proposto legitima, para o espaço litorâneo, os empreendimentos imobiliárioturísticos já instalados e incentiva a criação de novos. Paradoxalmente minimiza ou desconsidera o veraneio, preferindo enquadrar as zonas de praia às práticas turísticas. Nestes termos, a mera demarcação geométrica de áreas e zonas, não equaciona os conflitos de uso, pois desconsidera o conteúdo social do espaço.

Embora sem referência ao veraneio na proposta de zoneamento, a municipalidade impõe uma pesada taxação para o uso do espaço, nos termos do artigo 85 da Lei Orgânica Municipal, aprovada em 1989, com estipulação de acréscimo de impostos $(20 \%)$ à prática do veraneio, considerando-a como uso anti-social do imóvel.

Tal postura, de taxação diferenciada, denota um quadro de arrecadação insuficiente para suprir as crescentes demandas por infra-estrutura viária e hidrosanitária, principalmente em áreas com número de veranistas superior ao de moradores: praias como Presídio e Porto das Dunas. Acrescenta-se a isto uma grande inadimplência. Os problemas estão longe de uma resolução se continuarem a depender do orçamento municipal.

Lamentavelmente, reforça-se, com tal postura, a lógica em vigor há mais de trinta anos de demanda do mercado imobiliário. Continua o Poder Público Municipal "mero espectador", omisso às transformações que se sucedem. É o preço pago pela desconsideração, na explicitação clara de constituição da metrópole, da expansão do veraneio marítimo, principal elemento da urbanização do espaço litorâneo de Aquiraz.

O parcelamento do litoral de Aquiraz, mediado pelas normas elaboradas pelo poder Público Municipal, serviu aos interesses comerciais das empresas imobiliárias fortalezenses, caracterizou-se como fenômeno dinamizado da ocupação dos espaços a beira-mar por veranistas, ou melhor, de consumidores do litoral. Entretanto, o mesmo, não possibilitou aumento de arrecadação esperado, haja 
Veraneio marítimo na metrópole: o caso de Aquiraz, Ceará-Brasil Alexandre Queiroz Pereira, Eustógio Wanderley Correia Dantas

vista 77,9\% dos proprietários de imóveis cadastrados (média da última década) permanecerem na inadimplência.

\section{Os consumidores do litoral}

Os proprietários de imóveis cadastrados estão diretamente envolvidos na expansão do tecido urbano do espaço litorâneo de Aquiraz. A análise de cadastro da Secretaria de Finanças e Arrecadação do Município de Aquiraz possibilita reconhecê-los, embora às informações nele contidas, estejam desatualizadas Em geral, após a venda dos lotes, as pessoas físicas, jurídicas e as empresas imobiliárias não repassam à Prefeitura as informações pertinentes.

O Município de Aquiraz foi subdivido em 27 (vinte e sete) setores de cadastro e arrecadação. Em termos de espacialização, os núcleos destes setores são, na verdade, localidades que apresentam ocupação mais adensada (principalmente as de comunidades, loteamentos e segundas residências).

Destes, 19 (dezenove) concentram os maiores índices de proprietários não munícipes. Sua localização corresponde territorialmente ao que se considera espaço litorâneo aquiraense, ou seja, os Distritos Sede, Tapera e Jacaúna.

De todas as regiões brasileiras existem contribuintes cadastrados em Aquiraz, sendo 465 da região Sudeste, 144 do Centro-Oeste, 68 do Nordeste, 44 do Norte e 27 do Sul, inclusive de outros países, principalmente Portugal. No entanto, trata-se de fenômeno majoritariamente estadual partindo, principalmente, da capital: a grande maioria, 16.713, (mais de 90\%) e o restante, 986, provenientes de outros municípios cearenses.

Dados deste cadastro citam ainda que, em apenas 13(treze) bairros de Fortaleza, não se evidenciou a existência de proprietários de imóveis em Aquiraz, notadamente os habitados por pessoas de baixo poder aquisitivo.

Explicita-se, também, concentração de grande número de proprietários em poucos bairros de Fortaleza (Quadro 01), resultado de concentração sócio-espacial de renda na cidade.

Quadro 01: Relação dos bairros de Fortaleza por quantidade de proprietários de imóveis cadastrados em Aquiraz, por classe (variação do número de proprietários)

\section{De 001 a 100 proprietários/bairro}

São João do Tauape, Parangaba,Luciano Cavalcante, José Walter, Aeroporto, Barra do Ceará, Bela Vista, Passaré, Alagadiço Novo, Rodolfo Teófilo, Aerolândia, Parque Manibura, Bom Futuro, Serrinha, Alto da Balança, Cajazeiras, Vicente Pizón, Alagadiço, Amadeu Furtado, Vila Pery, Bom Jardim, Praia do Futuro, Conjunto Ceará, Parque Araxá, Álvaro Weyne, Sapiranga, Carlito Pamplona, Bom Sucesso, Cidade 2000, Quintino Cunha, Pici, Castelão, Parque Dois Irmãos, Pedras, Parreão, Pirambu, Vila Velha, Ancuri, Canidezinho, Jardim Guanabara, Parque Genibaú, Autran Nunes, Barroso, Cais do Porto, Presidente Kennedy, Siqueira, Paupina, Coaçu, Grajerú e São Miguel

\section{De 101 a 999 proprietários/bairro}

Dionísio Torres, Vila União, José Bonifácio, Parquelândia, Praia do Futuro II, Messejana, Cidade dos Funcionários, Bairro de Fátima, Cocó, Joaquim Távora, Varjota, Cambeba, Montese, Benfica e Edson Queiroz.

\section{De 1000 - 4704 proprietários/bairro}

Centro, Aldeota, Papicu, Meireles e Praia de Iracema.

Cadastro da Secretaria de Finanças e Arrecadação 2005.

Fonte: Prefeitura Municipal de Aquiraz. 
Em Fortaleza, segundo o Censo 2000, apenas $11,45 \%$ das famílias tinham renda superior a dez salários mínimos. Bairros como Aldeota, Meireles, Papicu e Praia de Iracema são, atualmente, conhecidos como bairros nobres, lugares de residências de classes mais abastadas. De acordo com os micros dados do IBGE (2000), no bairro Aldeota, 54,8\% dos moradores tem rendimento mensal superior a 5 salários mínimos, no Meireles este percentual é ainda maior, 57,5\%. Na Praia de Iracema este índice alcança a marca de $29,5 \%$ e no Papicu $37,2 \%$.

A condição atribuída a estes bairros foi constituída, historicamente, no século XX, a partir da transferência lenta dos moradores de Jacarecanga para o leste, construindo a Aldeota e suas adjacências (SILVA, 2005). Outros bairros como Parquelândia, Praia do Futuro, Messejana, Cidade dos Funcionários, Bairro de Fátima, Cocó, Joaquim Távora, Varjota, Edson Queiroz, Cambeba, Montese e Benfica, habitados por uma classe média, apresentam também grande número de proprietários de imóveis no espaço litorâneo de Aquiraz.

Assim sendo, a análise dos resultados do cruzamento da variável renda em Fortaleza com os dados cadastrais fornecidos pela Prefeitura Municipal de Aquiraz, indica que os moradores destes bairros com maiores índices de renda média são os principais proprietários de imóveis na área litorânea de Aquiraz.

Fica claro que as áreas valorizadas em Aquiraz, no segmento de propriedade de imóveis e veraneio, exclui as camadas populacionais da metrópole que não dispõem de uma renda superior a 5 salários mínimos.

\section{CONSIDERAÇÕES FINAIS}

A urbanização fomentada pelo veraneio marítimo é sutil e às vezes desconsiderada. A influência de Fortaleza na divulgação do veraneio marítimo revela o modo como o espaço litorâneo é abarcado pelo seu tecido urbano, evidenciando, também, a relação dialética entre valorização litorânea, veraneio marítimo e urbanização metropolitana.
O primeiro aspecto revelador da relação supracitada é a produção de uma expansão linear e descontinua do tecido urbano metropolitano.

Com a valorização litorânea, os veranistas, os empreendedores imobiliários, os moradores das localidades praianas, o Poder Público Municipal e Estadual se envolvem, direta e indiretamente, na formação de parcelamentos urbanos e de aglomerados de segundas residências.

Os termos evidenciados no PDDU, associados aos recursos do Projeto Estadual (PROURB) atestam tal assertiva. Fica explícita, tanto pelos projetos estruturantes propostos, quanto pelo zoneamento, a ênfase dada aos espaços litorâneos, espaço de expansão do tecido urbano fortalezense e enquadrado à perspectiva metropolitana.

Por conseguinte, a elaboração e, posteriormente, aprovação do PDDU pela Câmara Municipal não representou apenas interesses e demandas locais. Este plano enxerga o território de Aquiraz, suas benesses e potencialidades, destacando um contexto maior: o metropolitano. Mesmo respeitando os limites político-administrativos, as propostas vão além do município e articulam-se à Região Metropolitana de Fortaleza. As políticas adotadas pelo Município em foco apontam o espaço litorâneo como área prioritária, "disponível" à expansão da Metrópole cearense.

\section{BIBLIOGRAFIA}

AQUIRAZ. Código Tributário do Município de Aquiraz (Lei no . 566/2005). Aquiraz, 2005.

Plano Diretor de Desenvolvimento Urbano (PDDU). Aquiraz, 2001/2002.

\section{Lei orgânica do município de Aquiraz.} Aquiraz, 1989.

Lei de uso e ocupação do solo na faixa litorânea ( $n^{\circ}$. 33/84). Aquiraz, 1984. 
Veraneio marítimo na metrópole: o caso de Aquiraz, Ceará-Brasil Alexandre Queiroz Pereira, Eustógio Wanderley Correia Dantas

BERNAL, Cleide. A metrópole emergente: a ação do capital imobiliário na estruturação urbana de Fortaleza. Fortaleza: Editora UFC/Banco do Nordeste do Brasil S.A., 2004.

BRASIL. Lei do parcelamento do solo urbano $\left(\mathrm{n}^{\circ}\right.$. 6.766/79). Brasília, 1979.

CARLOS, Ana F. Alessandri. O Espaço Urbano. Novos escritos sobre a cidade. São Paulo: Contexto, 2004.

São Paulo: dinâmica urbana e metropolitana. In: Revista Território. Rio de Janeiro. Ano VII, $\mathrm{n}^{\mathrm{o}}$. 11, 12 e 13. set./out., 2003. p. 77-90.

O consumo do espaço. In: . (org.). Novos caminhos da geografia. São Paulo: Contexto, 1999. p. 173-186. (coleção caminhos da geografia).

A (Re)Produção do Espaço Urbano. São Paulo: Edusp, 1994.

COSTA, M. C. Lustosa. Urbanização da sociedade cearense. In. DAMIANI, A. L.; CARLOS, A. F. A.; SEABRA, O. C. de L. (orgs.) O espaço no fim de século: a nova raridade. 2 ed. São Paulo: Contexto, 2001, p. 100-117.

CORBIN, Alain. O território do vazio. A praia e o imaginário ocidental. Tradução de Paulo Neves. São Paulo: Companhia das Letras, 1989.

DANTAS, E. W. C. Da "capital do sertão" a "capital do sol": Fortaleza e o processo de "litoralização" do Ceará. In: SILVA, J. B.;DANTAS, E. W. C.; ZANELLA, M. E.; MEIRELES, A. J. A. Litoral e Sertão: natureza e sociedade no nordeste brasileiro. Fortaleza: Expressão Gráfica, 2006.

Fortaleza et le Ceará. Essai de geopolitique d'um pays de colonisation tardive: de la colonisation à mutation touristique contemporaine. Tese de Doutorado. Université de Paris IV Sorbonne, Paris, 2000.
Mar à Vista: estudo da maritimidade em Fortaleza: Fortaleza: Museu do Ceará, Secretaria de Cultura e Desporto, 2002.

O mar e o marítimo nos trópicos. In Revista Geousp. Espaço e tempo, São Paulo, nº 15, pp. 6376, 2004.

GOMES, M. P. Correia. O plano diretor de desenvolvimento urbano: após o Estatuto da Cidade. Rio de Janeiro, 2006. (digitado)

INSTITUTO DE BRASILEIRO DE GEOGRAFIA E ESTATÍSTICA (IBGE). Sinopse preliminar do censo demográfico 1991. Rio de Janeiro: IBGE, V.6, Número 5 (Ceará), p. 1-112, 1991.

Sinopse preliminar do censo demográfico 2000. Rio de Janeiro: IBGE, V.7, 2000.

LEFEVBRE, Henri. La production de l'espace. Paris: Éditions Anthropos, 1986.

LEFEVBRE, Henri. A revolução urbana. Tradução de Sérgio Martins. Belo Horizonte: EdUFMG, 1999.

O direito à cidade. Tradução de Rubens Eduardo Frias. $3^{a}$ ed. São Paulo: Centauro, 2004.

MADRUGA, A. Moacyr. Litoralização: da fantasia de liberdade à modernidade autofágica. Dissertação de Mestrado. 155f. FFLCH/USP. São Paulo, 1992.

MONTENEGRO JR., Inácio R. Pessoa. Turismo e urbanização: gestão de impactos no litoral de Aquiraz - CE. Dissertação de Mestrado. PRODEMA/UFC. 239 f. Fortaleza, 2004.

MORAES, A. C. R. Contribuições para a gestão da zona costeira do Brasil. Elementos para uma geografia do litoral brasileiro. São Paulo: HUCITEC, 1999.

PEREIRA, A. Q. Veraneio marítimo e expansão metropolitana no Ceará: Fortaleza em Aquiraz. 
Veraneio marítimo na metrópole: o caso de Aquiraz, Ceará-Brasil Alexandre Queiroz Pereira, Eustógio Wanderley Correia Dantas

Dissertação de Mestrado em Geografia- Universidade Federal do Ceará.157 f. Fortaleza, 2006.

SEABRA, Odette C. de Lima. A muralha que cerca o mar: uma modalidade de uso do solo urbano. Dissertação de Mestrado. FFLCH/USP. 122 f. São Paulo, 1979.

SILVA, José Borzacchiello da. Nas trilhas da cidade. $2^{a}$ ed. Fortaleza: Museu do Ceará, Secretaria da Cultura do Ceará, 2005.

Cidadania, lugar e globalização. In: VALENÇA, M. M.; GOMES, Rita de C. da Conceição (orgs.). Globalização e Desigualdades. Natal: A. S. Editores, 2002. p. 136-151.

A cidade contemporânea no Ceará. In: SOUZA, Simone(org.). Uma nova história do Ceará. Fortaleza: Fundação Demócrito Rocha, 2000.

A região metropolitana de Fortaleza. In: SILVA, J. B. da; CAVALCANTE, T. C; DANTAS, E. W. C. (orgs.). Ceará: um novo olhar geográfico. Fortaleza: Ed. Demócrito Rocha, 2005. p. 101-124.

SPOSITO, M. E. Beltrão. A urbanização da sociedade: reflexões para um debate sobre as novas formas espaciais. In. DAMIANI, A. L.; CARLOS, A. F. A.; SEABRA, O. C. de L. (orgs.) O espaço no fim de século: a nova raridade. 2 ed. São Paulo: Contexto, 2001, p. 83-99.

Espaços urbanos: territorialidades e representações. In: SPOSITO, E. S. (org). Dinâmica econômica, poder e novas territorialidades. Presidente Prudente: UNESP/FCT, 1999. p. 13-29.

URBAIN, Jean-Didier. Sur la Plage. Paris: Petite Bibliotéque Payot, 1995. 